\title{
A Review of Time Courses and Predictors of Lipid Changes with Fenofibric Acid-Statin Combination
}

\author{
Theodosios D. Filippatos
}

Published online: 17 May 2012

(C) The Author(s) 2012. This article is published with open access at Springerlink.com

\begin{abstract}
Fibrates activate peroxisome proliferator activated receptor $\alpha$ and exert beneficial effects on triglycerides, high-density lipoprotein cholesterol, and low density lipoprotein subspecies. Fenofibric acid (FA) has been studied in a large number of patients with mixed dyslipidemia, combined with a low- or moderate-dose statin. The combination of FA with simvastatin, atorvastatin and rosuvastatin resulted in greater improvement of the overall lipid profile compared with the corresponding statin dose. The long-term efficacy of FA combined with low- or moderate- dose statin has been demonstrated in a wide range of patients, including patients with type 2 diabetes mellitus, metabolic syndrome, or elderly subjects. The FA and statin combination seems to be a reasonable option to further reduce cardiovascular risk in high-risk populations, although trials examining cardiovascular disease events are missing.
\end{abstract}

Key words Fenofibric acid · Fibrate · Statin · Simvastatin . Atorvastatin · Rosuvastatin · Triglycerides · High-density lipoprotein cholesterol

\section{Introduction}

Fibrates have been used in the treatment of dyslipidemia for many years. Fibrates exert their effects by activating peroxisome proliferator activated receptor $\alpha$ (PPAR- $\alpha$ ) [1]. Fibrates are well known for their beneficial effects on triglycerides (TG), high-density lipoprotein cholesterol

T. D. Filippatos $(\bowtie)$

Department of Internal Medicine, School of Medicine,

University of Ioannina,

45110 Ioannina, Greece

e-mail: filtheo@gmail.com
(HDL-C), and low-density lipoprotein (LDL) subclass distribution $[2,3]$. One of the most used fibrates, fenofibrate, has also shown to improve many other atherosclerosis-related variables, such as high sensitivity C-reactive protein (hsCRP), lipoprotein-associated phospholipase $\mathrm{A}_{2}\left(\mathrm{LpPLA}_{2}\right)$, apolipoprotein $\mathrm{C}$-III (apoC-III), and reverse HDL cholesterol transport [1, 4-10].

Fenofibrate is a pro-drug, which requires de-esterification in the liver to fenofibric acid, the active drug, which is then released into the plasma to activate PPAR- $\alpha$ in liver, vascular endothelium, adipocytes, and muscle cells $[11,12]$. The newer fibrate formulation, fenofibric acid (FA, Trilipix ${ }^{\circledR}$, Abbott), that was recently approved by the Food and Drug Administration (FDA), is the choline salt of fenofibric acid. FA is not a pro-drug and does not undergo first-pass hepatic metabolism [13]. FA is manufactured as delayed-release $45 \mathrm{mg}$ and $135 \mathrm{mg}$ capsules and can be taken without regard to meals. Upon multiple dosing, FA plasma levels reach steady state within 8 days [14]. FA is administered once daily [14].

In vitro studies using human liver microsomes indicate that FA is a weak inhibitor of CYP2C8, CYP2C19, and CYP2A6, and a mild to moderate inhibitor of CYP2C9 at therapeutic concentrations $[14,15]$. Since they are highly protein-bound, all fibric acid derivatives may increase the anticoagulant effect of coumarin derivatives [16, 17], thus the International Normalized Ratio should be carefully monitored. No clinically significant pharmacokinetic interaction has been observed between FA/fenofibrate and statin administration in humans [18-20]. FA administration should be avoided in patients who have severe renal impairment, and dose reduction is required in patients having mild to moderate renal impairment. No pharmacokinetic studies have been conducted in patients with hepatic impairment. FA has not been investigated in trials in pediatric patients. 
The aim of the present review is to describe the effects of FA administration combined with a statin in patients with mixed dyslipidemia and to highlight the long-term maintenance of these effects in a wide range of patients.

\section{Methods}

A PubMed/Scopus search was performed up to September 2011 using combinations of "fenofibric acid" with the following keywords: fibrate, fenofibrate, statin, simvastatin, atorvastatin, rosuvastatin, lipid-lowering medications, adverse effects, side effects, gastrointestinal, transaminases, creatine kinase, myopathy, safety. Randomised controlled trials, original papers, review articles and case reports that provide information regarding the pharmacology, lipid and non-lipid effects, duration of biochemical alterations, and adverse events of FA + statin combination are included in the present review. References of these articles were scrutinised for relevant articles.

\section{Designs of major fenofibric acid trials}

The efficacy and safety of FA has been evaluated in a large well-designed phase III clinical program consisting of three separate double-blind, randomized, active control trials (Fig. 1) [21]. In each trial patients were randomized in a ratio of $2: 2: 2: 2: 2: 1$ to one of six arms:

- Fenofibric acid $135 \mathrm{mg} /$ day

- Low-dose statin

- Medium-dose statin
- Fenofibric acid $135 \mathrm{mg} /$ day + low-dose statin

- Fenofibric acid $135 \mathrm{mg} /$ day + medium-dose statin

- High-dose statin

A single statin was given in each trial:

- Simvastatin 20, 40 or $80 \mathrm{mg} /$ day [22]

- Atorvastatin 20, 40 or $80 \mathrm{mg} /$ day [23]

- Rosuvastatin 10,20 or 40 mg/day [24]

Together, these studies investigated the safety and efficacy of FA $135 \mathrm{mg}$ /day as monotherapy and combined with three different statins [21]. The high-dose statin arms were not used for formal statistical comparisons, but served as a clinically relevant reference for assessment of efficacy and safety. They are not described in detail in this review. Primary efficacy endpoints were fasting mean/median percentage changes in HDL-C and TG (comparing each combination with corresponding statin-dose monotherapy) and LDL cholesterol (LDL-C) levels (comparing each combination with FA monotherapy). Inclusion criteria were elevated TG ( $\geq 150 \mathrm{mg} / \mathrm{dl}$ or $1.69 \mathrm{mmol} / \mathrm{L})$, decreased HDL-C levels $(<40 \mathrm{mg} / \mathrm{dl}$ or $1.03 \mathrm{mmol} / \mathrm{L}$ for men and $<50 \mathrm{mg} / \mathrm{dl}$ or $1.29 \mathrm{mmol} / \mathrm{L}$ for women), and elevated LDL-C levels $(\geq 130 \mathrm{mg} / \mathrm{dl}$ or $3.36 \mathrm{mmol} / \mathrm{L})$. All trials had a 6 -week dietary run-in/lipid therapy washout, a 12 -week treatment period, and a 30-day follow-up period.

Patients who completed these trials were eligible to enter a phase III open-label 1-year extension study [25]. A subset of these patients was in turn examined in a phase III, openlabel, 2-year extension study [26]. In the extension studies all patients received FA $135 \mathrm{mg}$ /day combined with the moderate dose of the statin to which they had originally been randomized (rosuvastatin $20 \mathrm{mg}$ /day, simvastatin $40 \mathrm{mg}$ /day or atorvastatin $20 \mathrm{mg}$ /day). Their primary purpose was the evaluation of the long-term safety of FA
Fig. 1 Design of the pivotal trials evaluating the efficacy and safety of the combined use of fenofibric acid (FA) with different statins in patients with mixed dyslipidemia

\section{Phase III Study Design}

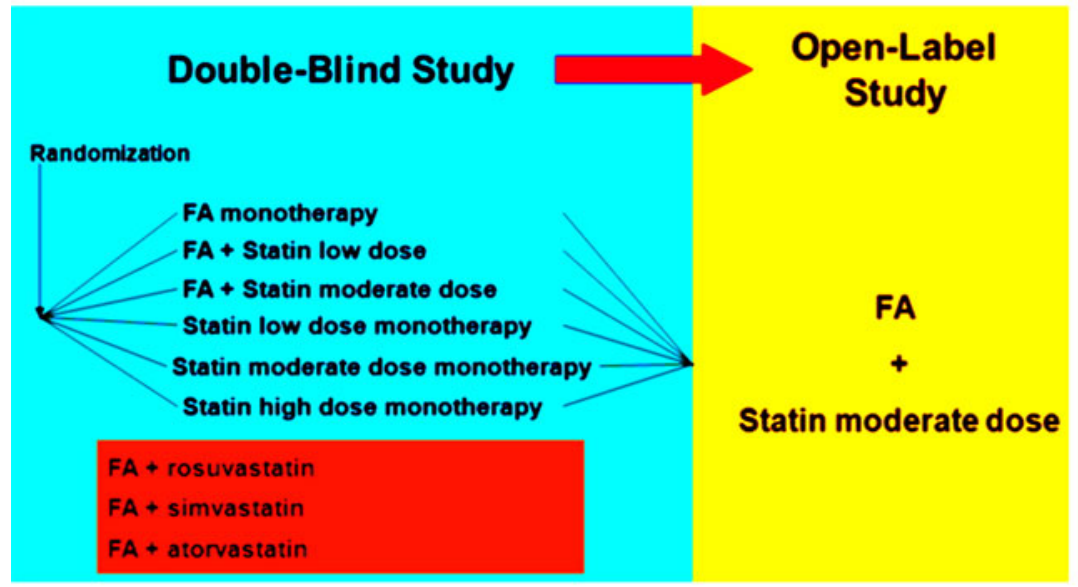


combined with these statins. Additionally, a pooled subgroup analysis of the randomized, double-blind trials was performed in 586 patients with mixed dyslipidemia and type 2 diabetes mellitus (T2DM) [27].

In another 8-week, randomized, double-blind study, the effect on LDL-C levels of the administration of simvastatin $40 \mathrm{mg} /$ day was compared with the fixed combination dosage of FA with rosuvastatin 5,10 or $20 \mathrm{mg} /$ day, in patients $(n=474)$ with LDL-C $\geq 160 \mathrm{mg} / \mathrm{dl}$ and $\leq 240 \mathrm{mg} / \mathrm{dl}$ and $\mathrm{TG} \geq 150 \mathrm{mg} / \mathrm{dl}$ and $<400 \mathrm{mg} / \mathrm{dl} \mathrm{[28]}$.

\section{Alterations in lipid profiles with FA, statins and FA + statin combinations}

The three Phase III trials together enrolled approximately 2,700 patients, of whom 2,575 were available for analysis.

The FA/simvastatin study randomized 657 patients of whom 621 were available for analysis [22]. FA + simvastatin $20 \mathrm{mg}$ /day produced a greater increase in HDL-C $(17.8 \%$ vs. $7.2 \%, p<0.001)$ and a greater decrease in TG levels $(-37.4 \%$ vs. $-14.2 \%, p<0.001)$ and very lowdensity lipoprotein cholesterol (VLDL-C) levels $(-38.9 \%$ vs. $-19.2 \%, p<0.01)$ compared with simvastatin $20 \mathrm{mg} /$ day (Fig. 2). In addition, FA + simvastatin $20 \mathrm{mg} /$ day resulted in a greater LDL-C decrease compared with FA monotherapy $(-24.0 \%$ vs. $-4.0 \%, p<0.001)$. Similarly, FA + simvastatin $40 \mathrm{mg} /$ day produced a greater increase in HDL-C (18.9\% vs. $8.5 \%, p<0.001)$ and a greater decrease in TG levels $(-42.7 \%$ vs. $-22.4 \%, p<0.001)$ and VLDL-C $(-51.1 \%$ vs. $-35.7 \%, p<0.01)$ compared with simvastatin $40 \mathrm{mg} /$ day, as well as a greater LDL-C decrease compared with FA monotherapy ( $-25.3 \%$ vs. $-4.0 \%, p<0.001)$ (Fig. 2). FA + simvastatin $20 \mathrm{mg} /$ day resulted in significantly greater reductions in non-HDL-C, VLDL-C, total cholesterol (TC) and apoB compared with simvastatin $20 \mathrm{mg} /$ day monotherapy $(p \leq 0.012)$. FA + simvastatin $40 \mathrm{mg} /$ day resulted in similar reductions in non-HDL-C, apoB, TC, and hsCRP compared with simvastatin $40 \mathrm{mg} /$ day [22].

The FA/atorvastatin study randomized 613 patients of whom 577 were available for analysis [23]. FA + atorvastatin $40 \mathrm{mg} /$ day combination resulted in significantly greater improvements in TG $(-42.1 \%$ vs. $-23.2 \%, p<0.001)$, VLDL-C $(-53.5 \%$ vs. $-35.6 \%, p<0.001)$ and HDL-C levels $(12.6 \%$ vs. $5.3 \%, p=0.01)$ compared with atorvastatin $40 \mathrm{mg} /$ day monotherapy, as well as a greater decrease in LDL-C concentration compared with FA monotherapy $(-35.4 \%$ vs. $-3.4 \%, p<0.001$, Fig. 3). Similar results were shown when $\mathrm{FA}+$ atorvastatin $20 \mathrm{mg}$ /day was compared with FA or atorvastatin $20 \mathrm{mg} /$ day monotherapy. Treatment with FA + atorvastatin $20 \mathrm{mg} /$ day resulted in significantly greater improvements in non-HDL-C compared with FA $(p<0.001)$ and atorvastatin $20 \mathrm{mg} /$ day monotherapies $(p<0.05$, Fig. 3) [23].

The FA/rosuvastatin study randomized 1,455 patients of whom 1,377 were available for analysis [24]. FA + rosuvastatin $20 \mathrm{mg}$ /day resulted in a significantly greater increase in HDL-C $(19.0 \%$ vs. $10.3 \%, p<0.001)$ and a significantly greater decrease in TG $(-42.9 \%$ vs. $-25.6 \%, p<0.001)$ and VLDL-C ( $-50.6 \%$ vs. $-42.1 \%, p=0.038)$ levels compared with rosuvastatin $20 \mathrm{mg} /$ day monotherapy (Fig. 4). Furthermore, $\mathrm{FA}+$ rosuvastatin $20 \mathrm{mg} /$ day produced a significantly greater LDL-C reduction $(-38.8 \%$ vs. $-6.5 \%, p<0.001)$ compared with FA monotherapy. Similar results were observed when FA + rosuvastatin $10 \mathrm{mg}$ /day was compared with rosuvastatin $10 \mathrm{mg} /$ day or with FA monotherapy (Fig. 4). FA + rosuvastatin $10 \mathrm{mg} /$ day resulted in significantly greater improvements in non-HDL-C compared with FA $(p<0.001)$ and rosuvastatin $10 \mathrm{mg}$ /day monotherapy $(p<$ $0.001)$, as well as in hsCRP $(p=0.013)$ and VLDL-C $(p<$ 0.001 ) compared with rosuvastatin $10 \mathrm{mg} /$ day monotherapy. FA + rosuvastatin $20 \mathrm{mg}$ /day resulted in a greater improvement in hsCRP levels compared with rosuvastatin $20 \mathrm{mg} /$ day monotherapy $(p=0.01)$ [24].

In another Phase III, multicenter, randomized, doubleblind study, rosuvastatin $5 \mathrm{mg}$ /day was administered with
Fig. 2 Lipid alterations (\%) with the combination of fenofibric acid (FA) $135 \mathrm{mg} /$ day with simvastatin compared with simvastatin alone [22]. * $p<0.05$ vs. corresponding statin dose. \& $p<0.05$ vs. FA monotherapy. Bars represent mean $\pm \mathrm{SEM}$. The numbers with white color represent the baseline values, whereas the numbers with black color represent the percent changes. HDL-C $=$ high-density lipoprotein cholesterol, $\mathrm{TG}=$ triglycerides, LDL-C = lowdensity lipoprotein cholesterol

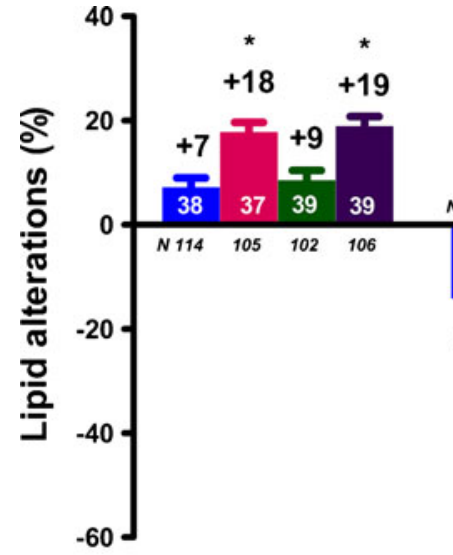

HDL-C

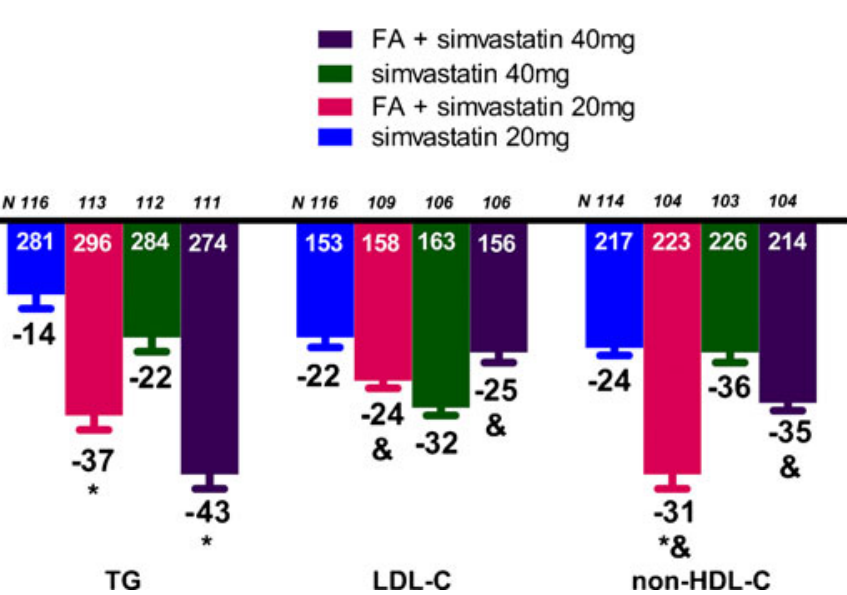


Fig. 3 Lipid alterations (\%) with the combination of fenofibric acid (FA) $135 \mathrm{mg} /$ day with atorvastatin compared with atorvastatin alone [23]. $*_{p}<0.05$ vs. corresponding statin dose. ${ }^{\&} p<0.05$ vs. FA monotherapy. Bars represent mean \pm SEM. The numbers with white color represent the baseline values, whereas the numbers with black color represent the percent changes. HDL-C = high-density lipoprotein cholesterol, $\mathrm{TG}=$ triglycerides, LDL-C $=$ low-density lipoprotein cholesterol

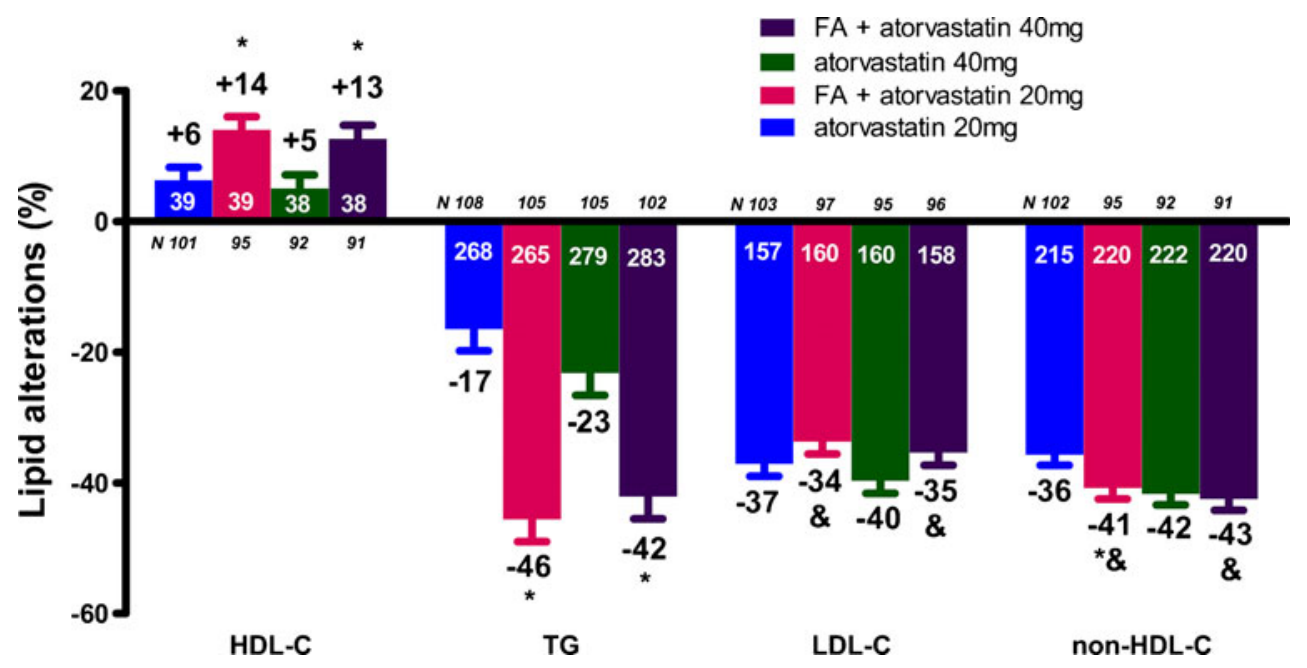

FA $135 \mathrm{mg} /$ day in patients with mixed dyslipidemia $(n=$ 758) for 12 weeks [29]. Combination treatment resulted in significantly greater improvements in plasma concentration of HDL-C (23.0 \% vs. $12.4 \%, p<0.001)$ and TG $(-40.3 \%$ vs. $-17.5 \%, p<0.001)$ compared with rosuvastatin monotherapy, as well as of LDL-C ( $-28.7 \%$ vs. $-4.1 \%, p<0.001)$ compared with FA monotherapy [29].

A recent trial randomized patients to receive fixed-dose combinations of FA $135 \mathrm{mg}$ /day with rosuvastatin 5,10 or $20 \mathrm{mg} /$ day or to monotherapy with simvastatin $40 \mathrm{mg} /$ day [28]. The combinations resulted in significantly greater decreases in plasma levels of LDL-C, non-HDL-C, apoB, TG, hsCRP, VLDL-C, TC, and apoC-III, and a significantly greater increase in HDL-C concentration, compared with simvastatin $40 \mathrm{mg} /$ day. For example the reductions in LDL-C levels with FA + rosuvastatin 5, 10 and $20 \mathrm{mg} /$ day were $38.9 \%, 46.0 \%$ and $47.2 \%$ respectively compared with $32.8 \%$ for simvastatin $40 \mathrm{mg} /$ day $(p<0.01)$. Significantly higher proportions of patients in each FA/rosuvastatin group achieved optimal levels for LDL-C $(<100 \mathrm{mg} / \mathrm{dl}$, $p<0.001)$, non-HDL-C $(<130 \mathrm{mg} / \mathrm{dl}, p<0.001)$, apoB $(<90 \mathrm{mg} / \mathrm{dl}, p \leq 0.02)$, and TG $(<150 \mathrm{mg} / \mathrm{dl}, p<0.001)$ compared with simvastatin $40 \mathrm{mg} /$ day monotherapy. Furthermore, significantly higher proportions of patients treated with each of the FA/rosuvastatin doses simultaneously achieved optimal LDL-C and non-HDL-C levels, as well as optimal levels for all five parameters (LDL-C, non-HDL$\mathrm{C}$, apoB, HDL-C, and TG), compared with simvastatin $40 \mathrm{mg} /$ day [28].

In a recent 12-week double-blind study, a total of 543 patients with $\mathrm{TG} \geq 150 \mathrm{mg} / \mathrm{dl}$ and $<400 \mathrm{mg} / \mathrm{dl}$, HDL$\mathrm{C}<40 \mathrm{mg} / \mathrm{dl}$ (<50 mg/dl for women), and LDL$\mathrm{C} \geq 130 \mathrm{mg} / \mathrm{dl}$ were randomized to $\mathrm{FA} 135 \mathrm{mg} /$ day or placebo, each co-administered with atorvastatin $40 \mathrm{mg} /$ day + ezetimibe $10 \mathrm{mg} /$ day (Atorva/Eze) [30]. Treatment with FA + Atorva/ Eze resulted in a significantly greater improvement in HDL-C (13.0\% vs. $4.2 \%, p<0.001)$ and TG levels $(-57.3 \%$ vs. $-39.7 \%, p<0.001)$ compared with Atorva/Eze. Both groups experienced a $>50 \%$ reduction in LDL-C concentration (-52.9 \% with FA + Atorva/Eze, $-52.0 \%$ with Atorva/ Eze). Furthermore, FA + Atorva/Eze resulted in a significantly greater effect on non-HDL-C, apoB, apoA-I, apoC-III, VLDL-C, and hsCRP compared with Atorva/Eze. More patients in the triple combination achieved the combined
Fig. 4 Lipid alterations (\%) with the combination of fenofibric acid (FA) $135 \mathrm{mg} /$ day with rosuvastatin compared with rosuvastatin alone [24]. ${ }^{*} p<0.05$ vs. corresponding statin dose. ${ }^{\text {\& }}$ $p<0.05$ vs. FA monotherapy. Bars represent mean \pm SEM. The numbers with white color represent the baseline values, whereas the numbers with black color represent the percent changes. HDL-C $=$ high-density lipoprotein cholesterol, $\mathrm{TG}=$ triglycerides, LDL-C = lowdensity lipoprotein cholesterol

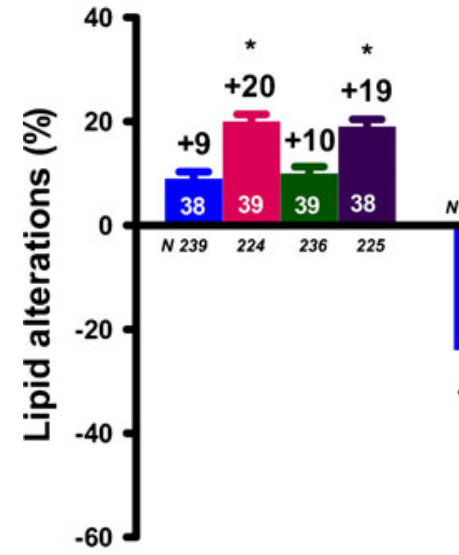

HDL-C
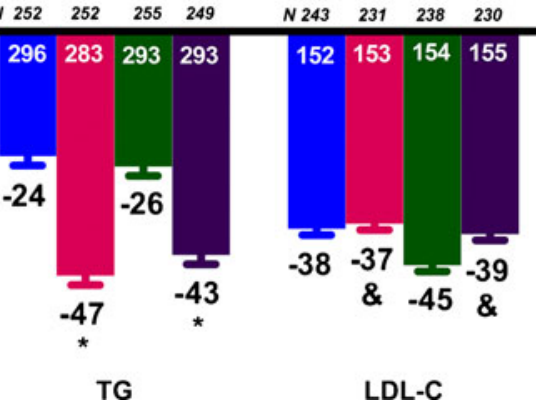

LDL-C

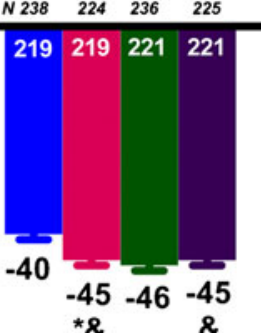

non-HDL-C 
target of LDL-C $<100 \mathrm{mg} / \mathrm{dl}$, non-HDL-C $<130 \mathrm{mg} / \mathrm{dl}$, and apoB $<90 \mathrm{mg} / \mathrm{dl}(88.4 \%$ vs $80.8 \%$ in Atorva/Eze) [30].

\section{Long-term maintenance of FA-induced metabolic effects}

The year 1 extension study reported sustained improvements versus baseline in numerous lipid parameters including TG, HDL-C, LDL-C, apoB, and hsCRP [25]. A total of 310 patients was enrolled and treated in the year 2 extension study, of whom $287(92.6 \%)$ patients completed the study [26]. The improvements in lipid parameters seen at 1 year were sustained for $\geq 2$ years. Pooled results showed substantial percentage changes in all efficacy variables with no evidence of attenuation of the effects over time [26]. In the pooled year 2 population, the change from baseline to week 116 was $+17.4 \%$ in HDL-C, $-46.4 \%$ in TG, $-40.4 \%$ in LDL$\mathrm{C},-47.3 \%$ in non-HDL-C, $-52.8 \%$ in VLDL-C and $-37.8 \%$ in TC levels. It should be mentioned that the observed alterations in non-HDL-C, TC and VLDL-C were significantly $(p<0.02)$ smaller in the FA + simvastatin group compared with the FA + atorvastatin or FA + rosuvastatin groups (Fig. 5) [26].

It should be mentioned that the number of patients included in the extension studies is low and it is most likely that highly motivated, good responders were included, a fact that could affect the observed results.

\section{Time courses and predictors of response}

In the FA + statin trials the significant differences in all primary lipid variables between both combination therapies and the corresponding monotherapies were generally observed after 4 weeks of treatment and sustained throughout 12 weeks [22-24]. Furthermore, the effect of treatment was different between certain subgroups of patients. For example, in the subgroup of patients with baseline LDL-C $>160 \mathrm{mg} / \mathrm{dl}$ $(n=247)$ the decreases in LDL-C were similar in the FA + simvastatin 20 and $40 \mathrm{mg} /$ day (-33.2\% and $-34.4 \%$,) and in the corresponding simvastatin $20 \mathrm{mg} /$ day $(-29.0 \%)$ and $40 \mathrm{mg} /$ day $(-34.9 \%)$ monotherapy groups. FA + simvastatin (20 or $40 \mathrm{mg}$ /day) had a greater treatment effect on LDL-C levels in women $(-29.7 \%$ and $-30.3 \%$, respectively) compared with men $(-19.0 \%$ and $-20.5 \%$, respectively) [22].

\section{Response to FA in patient subgroups}

In a recent post-hoc analysis of the three 12-week trials, the administration of FA + low- or moderate-dose statin in approximately 2,000 subjects with the metabolic syndrome was examined [31]. FA + low or moderate-dose statin reduced the number of patients meeting the American Heart Association/National Heart, Lung and Blood Institute (AHA/NHLBI) diagnostic criteria for metabolic syndrome [32] ( $-35.7 \%$ and $-35.9 \%$, respectively) compared with low-, moderate-, or high-dose statin monotherapy $(-15.5 \%,-16.6 \%$, and $-13.8 \%$, respectively) or FA monotherapy $(-25.7 \%)$. FA + low- or moderate-dose statin significantly decreased TG $(p<0.001)$ and increased HDL-C $(p<0.001)$ levels compared with the corresponding-dose statin. Interestingly, the prevalence of patients meeting the fasting blood glucose criterion decreased slightly with FA + statin or FA monotherapy but increased slightly with the administration of statin monotherapy. Furthermore, the mean change in fasting glucose was significantly different between FA + low- or moderate-dose statin and low- or moderate-dose statin monotherapy, respectively $(p \leq 0.002)$ [31]. Statins have been associated with a slightly increased risk for T2DM development [33]. The finding that the FA + statin combination attenuates the effects of statin on carbohydrate metabolism parameters needs further investigation.
Fig. 5 Two-year lipid alterations (\%) with the combination of fenofibric acid (FA) $135 \mathrm{mg} /$ day with moderate-dose statin [26]. Bars represent mean $\pm \mathrm{SD}$. The numbers with white color represent the baseline values, whereas the numbers with black color represent the percent changes. ${ }^{*} p<0.05$ vs. FA + simvastatin. HDL-C $=$ highdensity lipoprotein cholesterol, $\mathrm{TG}=$ triglycerides, LDL-C $=$ low-density lipoprotein cholesterol

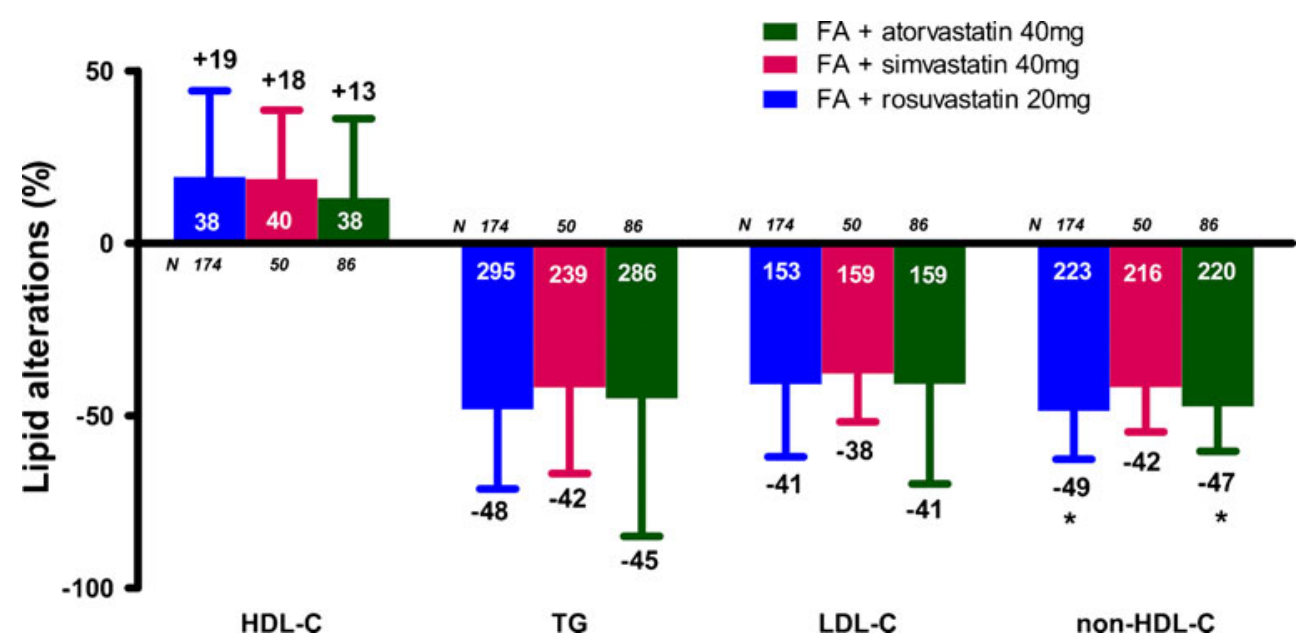


In patients with mixed dyslipidemia and T2DM at baseline $(n=586)$ the FA + low- or moderate-dose statin combination significantly $(p<0.05)$ reduced HDL-C, TG, and VLDL-C compared with the corresponding dose of statin monotherapy [27]. However, the LDL-C reduction, although similar between FA + low-dose statin and low-dose statin monotherapy, was smaller with FA + moderate-dose statin compared with moderate-dose statin monotherapy $(-32.6 \%$ vs. $-41.5 \%, p<0.01)$. It should be noted that in the subgroup with baseline LDL-C $>160 \mathrm{mg} / \mathrm{dl}$, the LDL-C reductions were similar with $\mathrm{FA}+$ low- or moderate dose statin $(-45.5 \%$ and $-43.5 \%$, respectively) compared with those observed with low- and moderate-dose statin monotherapy ( $-38.5 \%$ and $-47.1 \%$, respectively). Furthermore, the reductions in apoB and hsCRP plasma levels were similar between FA + low- or moderate- dose statin and the corresponding statin dose. In this population, it was also shown that the mean changes in fasting blood glucose levels with FA + low- or moderate-dose statin combination were significantly smaller ( $p=0.038$ and $p=0.040$, respectively) compared with the corresponding dose of statin monotherapy, with which mean fasting glucose levels increased [27].

In the 2-year extension study, the subgroup of patients with T2DM experienced improvement (similar with overall population) in HDL-C $(+15.0 \%)$, TG $(-42.1 \%)$, LDL-C $(-41.8 \%)$, non-HDL-C $(-48.2 \%)$, TC $(-39.4 \%)$ and VLDL-C (-54.6\%) levels, that was evident up to week 116 [26].

Data concerning the effect of hypolipidemic treatment in elderly subjects is limited. A recent post-hoc analysis evaluated data from patients aged $\geq 65$ years $(n=401)$ with mixed dyslipidemia who received either monotherapy with rosuvastatin 5,10 , or $20 \mathrm{mg} /$ day or FA $135 \mathrm{mg} /$ day, or combination therapy with rosuvastatin $(5,10$, or $20 \mathrm{mg} /$ day $)+$ FA $135 \mathrm{mg} /$ day, for 12 weeks in two randomized controlled trials [34]. Each dose of combination treatment decreased significantly the LDL-C concentration compared with FA monotherapy, as well as increased significantly HDL-C and decreased TG levels, compared with corresponding doses of rosuvastatin monotherapy $(p<0.001$ for all comparisons). LDL-C levels were not significantly different between FA + rosuvastatin and the corresponding dose of rosuvastatin monotherapy. The changes in LDL-C, HDL-C, and TG in the subgroup $(n=135)$ of elderly patients with T2DM in this study were similar to those seen in the overall population [34].

\section{Safety and tolerability of FA + statin combination}

Fibrates are generally safe and well tolerated. The most frequent adverse events (AEs), which are similar to those of statins, are gastrointestinal symptoms (nausea and diarrhea) and musculoskeletal symptoms [myalgia and moderate elevation of creatinine kinase $(\mathrm{CK})][1,35,36]$. Both fibrates and statins, especially in combination, have been reported to cause myopathy, but the most serious adverse effect, i.e. rhabdomyolysis, is rare if certain precautions are taken $[1,37,38]$. Risk factors for these AEs include renal or hepatic insufficiency, increased age, and several medications $[39,40]$. The fenofibrate plus statin combination has been reported to be safer compared with gemfibrozil plus statin combination [41]. In The Fenofibrate Intervention and Event Lowering in Diabetes (FIELD) study, no cases of rhabdomyolysis were described among approximately 900 patients receiving fenofibrate plus a statin [42]. Fenofibrate may also increase creatinine and homocysteine plasma levels [1, 43-48].

The safety of the newer formulation of FA, alone and in combination with low- and moderate- dose statin, was evaluated in the phase III clinical studies (Table 1). The results indicate a similar AE profile between the different FA + statin combination treatments. Furthermore, when the safety profile was examined according to the presence or not of metabolic syndrome, or in patients with T2DM, the AEs were similar with those observed in the overall population $[27,31]$. Additionally, the long-term safety of FA + statin was tested for up to 2 years $[25,26]$. The most common adverse events were headache, upper respiratory tract infection, nasopharyngitis, and back pain, with the incidence of all adverse events being similar across all combination treatment groups $[25,26]$. In these studies, no deaths or rhabdomyolysis were reported during 1- or 2-year follow-up $[25,26]$.

It should be mentioned that even with the triple combination of FA with atorvastatin/ezetimibe there was no significant difference in the rate of serious or treatment-related AEs and the overall incidence of such events was low [30]. Furthermore, in elderly subjects the safety profile of FA + rosuvastatin administration was generally similar with the individual monotherapies [34].

In conclusion, $\mathrm{FA}+$ statin combination treatment did not produce a significant increased rate of serious adverse events compared with monotherapy.

\section{Clinical implications}

Cardiovascular disease (CVD) constitutes the leading cause of death in developed countries. Current treatment guidelines focus on lowering LDL-C as the primary strategy for reducing CVD risk $[49,50]$. Statins are associated with a significant CVD risk reduction [51, 52]. However, in the clinical setting a large number of patients treated with lipidlowering therapies have persistent lipid abnormalities [53-55]. Furthermore, it is now established that patients 
Table 1 Summary of adverse events (AEs) recorded during phase III trials of FA with statins

\begin{tabular}{|c|c|c|c|c|c|c|c|}
\hline \multirow[t]{2}{*}{ Study } & \multirow{2}{*}{$\begin{array}{l}\text { Number of } \\
\text { patients }\end{array}$} & \multirow{2}{*}{$\begin{array}{l}\text { Treatment } \\
\text { related AEs } \\
(\%)\end{array}$} & \multirow{2}{*}{$\begin{array}{l}\text { Rate of discontinuation } \\
\text { due to AEs }(\%)\end{array}$} & \multicolumn{4}{|c|}{$\%$ patients experiencing $\mathrm{AE}$} \\
\hline & & & & Myalgia & $\begin{array}{l}\text { Abnormal liver } \\
\text { function tests }{ }^{\mathrm{a}}\end{array}$ & $\begin{array}{l}\text { Increased } \\
\text { creatine } \\
\text { kinase }^{b}\end{array}$ & $\begin{array}{l}\text { Rhabdo- } \\
\text { myolysis }\end{array}$ \\
\hline FA and simvastatin [22] & 591 & 23.9 & 14.6 & 4.1 & 0.8 & 0.5 & 0 \\
\hline FA 135 mg/day & 119 & 32.8 & NR & 5.0 & 4.2 & 0 & 0 \\
\hline Simvastatin $20 \mathrm{mg} /$ day & 119 & 16.0 & 11.8 & 3.4 & 0 & 0 & 0 \\
\hline $\begin{array}{l}\text { FA } 135 \mathrm{mg} / \text { day }+ \\
\text { simvastatin } 20 \mathrm{mg} / \text { day }\end{array}$ & 119 & 22.7 & NR & 4.2 & 0 & 0.8 & 0 \\
\hline Simvastatin $40 \mathrm{mg} /$ day & 116 & 24.1 & NR & 5.2 & 0 & 1.7 & 0 \\
\hline $\begin{array}{l}\text { FA } 135 \mathrm{mg} / \text { day }+ \\
\text { simvastatin } 40 \mathrm{mg} / \text { day }\end{array}$ & 118 & 23.7 & NR & 2.5 & 0 & 0 & 0 \\
\hline FA and atorvastatin [23] & 554 & 16.0 & 8.5 & 4.1 & 1.1 & 0.2 & 0 \\
\hline FA 135 mg/day & 112 & 12.5 & 7.1 & 2.7 & 0 & 0 & 0 \\
\hline Atorvastatin $20 \mathrm{mg} /$ day & 113 & 6.2 & 2.7 & 4.4 & 0 & 0.9 & 0 \\
\hline $\begin{array}{l}\text { FA } 135 \mathrm{mg} / \text { day }+ \\
\text { atorvastatin } 20 \mathrm{mg} / \text { day }\end{array}$ & 110 & $20.0^{*}$ & $10.9^{*}$ & 1.8 & 2.7 & 0 & 0 \\
\hline Atorvastatin $40 \mathrm{mg} / \mathrm{day}$ & 109 & 18.3 & 11.0 & 7.3 & 0 & 0 & 0 \\
\hline $\begin{array}{l}\text { FA } 135 \mathrm{mg} / \text { day }+ \\
\text { atorvastatin } 40 \mathrm{mg} / \text { day }\end{array}$ & 110 & 22.7 & 12.7 & 4.5 & 2.7 & 0 & 0 \\
\hline FA and rosuvastatin [24] & 533 & NR & NR & 2.6 & 0.9 & 0.2 & 0 \\
\hline FA 135 mg/day & 105 & NR & NR & 1.0 & 1.9 & 0 & 0 \\
\hline Rosuvastatin $10 \mathrm{mg} /$ day & 105 & 16.9 & NR & 5.7 & 0 & 0 & 0 \\
\hline $\begin{array}{l}\text { FA } 135 \mathrm{mg} / \text { day }+ \\
\text { rosuvastatin } 10 \mathrm{mg} / \text { day }\end{array}$ & 106 & $27.2^{*}$ & NR & 1.9 & 1.9 & 1.0 & 0 \\
\hline Rosuvastatin $20 \mathrm{mg} /$ day & 107 & NR & NR & 1.9 & 0 & 0 & 0 \\
\hline $\begin{array}{l}\text { FA } 135 \mathrm{mg} / \text { day }+ \\
\text { rosuvastatin } 20 \mathrm{mg} / \text { day }\end{array}$ & 110 & NR & NR & 2.7 & 0.9 & 0 & 0 \\
\hline $\begin{array}{l}\text { FA and rosuvastatin versus } \\
\text { simvastatin alone }[28]\end{array}$ & 474 & 15.0 & 4.2 & NR & $0.7 / 0.2(\mathrm{ALT} / \mathrm{AST})$ & 0.4 & 0 \\
\hline Simvastatin $40 \mathrm{mg} /$ day & 119 & 16.8 & 5.9 & NR & $0 / 0$ & 0 & 0 \\
\hline $\begin{array}{l}\text { FA } 135 \mathrm{mg} / \text { day }+ \\
\text { rosuvastatin } 5 \mathrm{mg} / \text { day }\end{array}$ & 118 & 13.6 & 5.1 & NR & $0 / 0$ & 0 & 0 \\
\hline $\begin{array}{l}\text { FA } 135 \mathrm{mg} / \text { day }+ \\
\text { rosuvastatin } 10 \mathrm{mg} / \text { day }\end{array}$ & 119 & 14.3 & 2.5 & NR & $0.8 / 0$ & 0 & 0 \\
\hline $\begin{array}{l}\text { FA } 135 \mathrm{mg} / \text { day }+ \\
\text { rosuvastatin } 20 \mathrm{mg} / \text { day }\end{array}$ & 118 & 15.3 & 3.4 & NR & $1.7 / 0.9$ & 1.7 & 0 \\
\hline
\end{tabular}

${ }^{\mathrm{a}}$ ALT or AST $>3 \times$ ULN

${ }^{\mathrm{b}}$ Creatine kinase $>5 \times$ ULN

* Significant difference compared to the low-dose statin monotherapy $(p<0.05)$

$A E$, adverse event; $F A$, fenofibric acid; $A L T$, alanine aminotransferase; $A S T$, aspartate aminotransferase; $F A$, fenofibric acid; $U L N$, upper limit of normal; $N R$, not reported

are still at risk for CVD events, i.e. they have residual CVD risk, even if they are receiving optimal statin treatment [56]. The residual CVD risk remains even if statins are administrated in maximum doses. For example, in the Study of The Effectiveness of Additional Reductions in Cholesterol and Homocysteine (SEARCH), simvastatin $80 \mathrm{mg} /$ day reduced major vascular events by only $6 \%$ compared with simvastatin $20 \mathrm{mg} /$ day [57]. Furthermore, the elevation of the statin dose was associated with an increased risk of myopathy [57]. Residual CVD risk is at least partly explained by the increased levels of TGs and the decreased levels of HDL-C $[58,59]$. This risk is enhanced in patients with mixed dyslipidemia, such as T2DM patients or patients with metabolic syndrome, who are characterized by both increased TG levels and decreased HDL-C concentration. Factors which are also implicated, among others, in the increased residual CVD risk in patients with mixed dyslipidemia are the increased levels of the atherogenic small dense LDL particles, of apoC-III and of inflammation-related markers, such as hsCRP and Lp-PLA 2 [60-64]. A number of 
interventions have been shown to alter these parameters [65-77]. Fibrates, alone or combined with other drugs, have been demonstrated to reduce plasma levels of the small dense LDL particles and to induce a LDL phenotype modification [1, 3, 78-83]. Furthermore, evidence exists that fibrates improve inflammation-related parameters $[10$, 83-86]. There is also evidence that fibrates can alter HDL particle distribution, which may play a role in the residual CVD risk [87, 88].

The fibrate-statin combination may substantially reduce the residual CVD risk in certain populations. For example, the Action to Control Cardiovascular Risk in Diabetes (ACCORD) Lipid study included 5,518 patients with T2DM treated with open-label simvastatin, who were randomised to receive either masked fenofibrate or placebo for 4.7 years [89]. The annual rate of the primary outcome (first occurrence of nonfatal myocardial infarction, nonfatal stroke, or death from CVD causes) was $2.2 \%$ in the fenofibrate group and $2.4 \%$ in the placebo group [hazard ratio in the fenofibrate group, 0.92 ; $95 \%$ confidence interval (CI), 0.79-1.08; $p=$ 0.32)]. The annual death rate was $1.5 \%$ in the fenofibrate group and $1.6 \%$ in the placebo group (hazard ratio, 0.91; $95 \%$ CI, 0.75-1.10; $p=0.33$ ) [89]. However, in a prespecified analysis, a benefit regarding the primary outcome rate (first occurrence of nonfatal myocardial infarction, nonfatal stroke, or death from CVD causes) for patients with both a high baseline TG level $(\geq 204 \mathrm{mg} / \mathrm{dl})$ and a low HDL-C baseline level $(\leq 34 \mathrm{mg} / \mathrm{dl})$ was recognized for those on the simvastatin + fenofibrate combination [89]. In fact, this benefit was seen with no evidence of increased adverse events. In the ACCORD Lipid study, elevations of $\mathrm{CK} \geq 10$ times the upper limit of the normal range were similar in the fenofibrate group $(0.4 \%)$ and in the placebo group $(0.3 \%, p=0.83)$ and the same rate of any myopathy/myositis/rhabdomyolysis was reported in the 2 treatment groups $(0.1 \%)$ [89].

The evidence derived from randomized trials favors the use of FA combined with a low- or moderate-dose statin for the reduction of the residual CVD risk. This combination improves all primary lipid variables. For example, the percentage of patients simultaneously achieving LDL-C $<100 \mathrm{mg} / \mathrm{dl}$, nonHDL-C $<130 \mathrm{mg} / \mathrm{dl}$, apoB $<90 \mathrm{mg} / \mathrm{dl}$, HDL-C $>40 \mathrm{mg} / \mathrm{dl}$ (men) or $>50 \mathrm{mg} / \mathrm{dl}$ (women), and TG $<150 \mathrm{mg} / \mathrm{dl}$ was $\geq 5$-fold higher with the combination of FA + low-dose statin compared with low-dose statin monotherapy, and approximately 7-fold higher with the combination of FA + moderate-dose statin compared with moderate-dose statin monotherapy $(p<0.001$ for both) [27]. FA added to statin therapy has also repeatedly been shown to reduce hsCRP levels. This may be of clinical relevance since the reduction of hsCRP levels with rosuvastatin has been associated with CVD event decrease [90]. However, it should be mentioned that there is no clinical outcomes data to show that treating the non-LDL-C variables with FA will reduce major CVD endpoints.
Disclosure Editorial assistance for this article was provided by Adelphi Communications Limited, a medical education agency, with support from Abbott Pharmaceuticals. TD Filippatos was solely responsible for the content of this review and received no payment for its preparation.

Open Access This article is distributed under the terms of the Creative Commons Attribution License which permits any use, distribution, and reproduction in any medium, provided the original author(s) and the source are credited.

\section{References}

1. Filippatos T, Milionis HJ. Treatment of hyperlipidaemia with fenofibrate and related fibrates. Expert Opin Investig Drugs. 2008; 17:1599-614.

2. Filippatos TD, Elisaf MS. Fenofibrate plus simvastatin (fixed-dose combination) for the treatment of dyslipidaemia. Expert Opin Pharmacother. 2011;12:1945-58.

3. Agouridis AP, Filippatos TD, Derdemezis CS, Mikhailidis DP, Elisaf MS. Combination of fenofibrate with non-statin drug regimens. Curr Pharm Des. 2010;16:3401-16.

4. Rosenson RS. Fenofibrate reduces lipoprotein associated phospholipase A2 mass and oxidative lipids in hypertriglyceridemic subjects with the metabolic syndrome. Am Heart J. 2008;155:499e9-16.

5. Chan DC, Watts GF, Ooi EM, Ji J, Johnson AG, Barrett PH. Atorvastatin and fenofibrate have comparable effects on VLDLapolipoprotein C-III kinetics in men with the metabolic syndrome. Arterioscler Thromb Vasc Biol. 2008;28:1831-7.

6. Hamilton SJ, Chew GT, Davis TM, Watts GF. Fenofibrate improves endothelial function in the brachial artery and forearm resistance arterioles of statin-treated Type 2 diabetic patients. Clin Sci (Lond). 2010;118:607-15.

7. Genest Jr J, Nguyen NH, Theroux P, Davignon J, Cohn JS. Effect of micronized fenofibrate on plasma lipoprotein levels and hemostatic parameters of hypertriglyceridemic patients with low levels of high-density lipoprotein cholesterol in the fed and fasted state. J Cardiovasc Pharmacol. 2000;35:164-72.

8. Filippatos T, Tsimihodimos V, Kostapanos M, Kostara C, Bairaktari E, Kiortsis D, et al. Analysis of the 6-month effect of orlistat, alone or in combination with fenofibrate, administration on triglyceride-rich lipoprotein metabolism in overweight and obese patients with metabolic syndrome. J Clin Lipidol. 2008;2:279-84.

9. Rosenson RS. Effect of fenofibrate on adiponectin and inflammatory biomarkers in metabolic syndrome patients. Obesity (Silver Spring). 2009;17:504-9.

10. Belfort R, Berria R, Cornell J, Cusi K. Fenofibrate reduces systemic inflammation markers independent of its effects on lipid and glucose metabolism in patients with the metabolic syndrome. J Clin Endocrinol Metab. 2010;95:829-36.

11. Chapman MJ. Pharmacology of fenofibrate. Am J Med. 1987;83:21-5.

12. Moutzouri E, Kei A, Elisaf MS, Milionis HJ. Management of dyslipidemias with fibrates, alone and in combination with statins: role of delayed-release fenofibric acid. Vasc Health Risk Manag. 2010;6:525-39.

13. Trilipix [Package insert]. North Chicago, IL: Abbott Laboratories; 2009. Available from: http://www.trilipixpro.com/. Accessed on May 26, 2010.

14. Alagona Jr P. Fenofibric acid: a new fibrate approved for use in combination with statin for the treatment of mixed dyslipidemia. Vasc Health Risk Manag. 2010;6:351-62. 
15. Prueksaritanont T, Richards KM, Qiu Y, Strong-Basalyga K, Miller A, Li C, et al. Comparative effects of fibrates on drug metabolizing enzymes in human hepatocytes. Pharm Res. 2005;22:71-8.

16. Schelleman H, Bilker WB, Brensinger CM, Wan F, Yang YX, Hennessy S. Fibrate/Statin initiation in warfarin users and gastrointestinal bleeding risk. Am J Med. 2010;123:151-7.

17. Kim KY, Mancano MA. Fenofibrate potentiates warfarin effects. Ann Pharmacother. 2003;37:212-5.

18. Martin PD, Dane AL, Schneck DW, Warwick MJ. An open-label, randomized, three-way crossover trial of the effects of coadministration of rosuvastatin and fenofibrate on the pharmacokinetic properties of rosuvastatin and fenofibric acid in healthy male volunteers. Clin Ther. 2003;25:459-71.

19. Zhu T, Awni WM, Hosmane B, Kelly MT, Sleep DJ, Stolzenbach JC, et al. ABT-335, the choline salt of fenofibric acid, does not have a clinically significant pharmacokinetic interaction with rosuvastatin in humans. J Clin Pharmacol. 2009;49:63-71.

20. Davidson MH. Statin/fibrate combination in patients with metabolic syndrome or diabetes: evaluating the risks of pharmacokinetic drug interactions. Expert Opin Drug Saf. 2006;5:145-56.

21. Jones PH, Bays HE, Davidson MH, Kelly MT, Buttler SM, Setze $\mathrm{CM}$, et al. Evaluation of a new formulation of fenofibric acid, ABT335, co-administered with statins: study design and rationale of a phase III clinical programme. Clin Drug Investig. 2008;28:625-34.

22. Mohiuddin SM, Pepine CJ, Kelly MT, Buttler SM, Setze CM, Sleep DJ, et al. Efficacy and safety of ABT-335 (fenofibric acid) in combination with simvastatin in patients with mixed dyslipidemia: a phase 3, randomized, controlled study. Am Heart J. 2009;157:195-203.

23. Goldberg AC, Bays HE, Ballantyne CM, Kelly MT, Buttler SM, Setze CM, et al. Efficacy and safety of ABT-335 (fenofibric acid) in combination with atorvastatin in patients with mixed dyslipidemia. Am J Cardiol. 2009;103:515-22.

24. Jones PH, Davidson MH, Kashyap ML, Kelly MT, Buttler SM, Setze CM, et al. Efficacy and safety of ABT-335 (fenofibric acid) in combination with rosuvastatin in patients with mixed dyslipidemia: a phase 3 study. Atherosclerosis. 2009;204:208-15.

25. Bays H, Jones P, Mohiuddin S, Kelly M, Sun H, Setze C, et al. Long-term safety and efficacy of fenofibric acid in combination with statin therapy for the treatment of patients with mixed dyslipidemia. J Clin Lipidol. 2008;2:426-35.

26. Kipnes MS, Roth EM, Rhyne JM, Setze CM, Lele A, Kelly MT, et al. Year two assessment of fenofibric acid and moderate-dose statin combination: a phase 3, open-label, extension study. Clin Drug Investig. 2010;30:51-61.

27. Jones PH, Cusi K, Davidson MH, Kelly MT, Setze CM, Thakker $\mathrm{K}$, et al. Efficacy and safety of fenofibric acid co-administered with low- or moderate-dose statin in patients with mixed dyslipidemia and type 2 diabetes mellitus: results of a pooled subgroup analysis from three randomized, controlled, double-blind trials. Am J Cardiovasc Drugs. 2010;10:73-84.

28. Roth EM, McKenney JM, Kelly MT, Setze CM, Carlson DM, Gold A, et al. Efficacy and safety of rosuvastatin and fenofibric acid combination therapy versus simvastatin monotherapy in patients with hypercholesterolemia and hypertriglyceridemia: a randomized, double-blind study. Am J Cardiovasc Drugs. 2010;10:175-86.

29. Roth EM, Rosenson RS, Carlson DM, Fukumoto SM, Setze CM, Blasetto JW, et al. Efficacy and safety of rosuvastatin $5 \mathrm{mg}$ in combination with fenofibric acid $135 \mathrm{mg}$ in patients with mixed dyslipidemia - a phase 3 study. Cardiovasc Drugs Ther. 2010;24:421-8

30. Jones PH, Goldberg AC, Knapp HR, Kelly MT, Setze CM, Stolzenbach JC, et al. Efficacy and safety of fenofibric acid in combination with atorvastatin and ezetimibe in patients with mixed dyslipidemia. Am Heart J. 2010;160:759-66.

31. Bays HE, Roth EM, McKenney JM, Kelly MT, Thakker KM, Setze CM, et al. The effects of fenofibric acid alone and with statins on the prevalence of metabolic syndrome and its diagnostic components in patients with mixed dyslipidemia. Diabetes Care. 2010;33:2113-6.

32. Grundy SM, Cleeman JI, Daniels SR, Donato KA, Eckel RH, Franklin BA, et al. Diagnosis and management of the metabolic syndrome: an American Heart Association/National Heart, Lung, and Blood Institute Scientific Statement. Circulation. 2005;112:2735-52.

33. Sattar N, Preiss D, Murray HM, Welsh P, Buckley BM, de Craen AJ, et al. Statins and risk of incident diabetes: a collaborative metaanalysis of randomised statin trials. Lancet. 2010;375:735-42.

34. Pepine CJ, Jacobson TA, Carlson DM, Kelly MT, Setze CM, Gold A, et al. Combination rosuvastatin plus fenofibric acid in a cohort of patients 65 years or older with mixed dyslipidemia: subanalysis of two randomized, controlled studies. Clin Cardiol. 2010;33:609-19.

35. Florentin M, Liberopoulos EN, Mikhailidis DP, Elisaf MS. Fibrateassociated adverse effects beyond muscle and liver toxicity. Curr Pharm Des. 2008;14:574-87.

36. Kiortsis DN, Filippatos TD, Mikhailidis DP, Elisaf MS, Liberopoulos EN. Statin-associated adverse effects beyond muscle and liver toxicity. Atherosclerosis. 2007;195:7-16.

37. Rosenson RS. Current overview of statin-induced myopathy. Am J Med. 2004;116:408-16.

38. Davidson MH, Armani A, McKenney JM, Jacobson TA. Safety considerations with fibrate therapy. Am J Cardiol. 2007;99:3C$18 \mathrm{C}$.

39. Taher TH, Dzavik V, Reteff EM, Pearson GJ, Woloschuk BL, Francis GA. Tolerability of statin-fibrate and statin-niacin combination therapy in dyslipidemic patients at high risk for cardiovascular events. Am J Cardiol. 2002;89:390-4.

40. Thompson PD, Clarkson P, Karas RH. Statin-associated myopathy. JAMA. 2003;289:1681-90.

41. Jones PH, Davidson MH. Reporting rate of rhabdomyolysis with fenofibrate + statin versus gemfibrozil + any statin. Am J Cardiol. 2005;95:120-2.

42. Keech A, Simes RJ, Barter P, Best J, Scott R, Taskinen MR, et al. Effects of long-term fenofibrate therapy on cardiovascular events in 9795 people with type 2 diabetes mellitus (the FIELD study): randomised controlled trial. Lancet. 2005;366:1849-61.

43. Filippatos TD, Kiortsis DN, Liberopoulos EN, Georgoula M, Mikhailidis DP, Elisaf MS. Effect of orlistat, micronised fenofibrate and their combination on metabolic parameters in overweight and obese patients with the metabolic syndrome: the FenOrli study. Curr Med Res Opin. 2005;21:1997-2006.

44. Tsimihodimos V, Kakafika A, Elisaf M. Fibrate treatment can increase serum creatinine levels. Nephrol Dial Transplant. 2001;16:1301.

45. Tsimihodimos V, Bairaktari E, Elisaf M. Fibrate-induced increase in serum urea and creatinine levels. Nephrol Dial Transplant. 2002; $17: 682$.

46. Tsimihodimos V, Miltiadous G, Bairaktari E, Elisaf M. Possible mechanisms of the fibrate-induced increase in serum creatinine. Clin Nephrol. 2002;57:407-8.

47. Dierkes J, Westphal S, Luley C. The effect of fibrates and other lipid-lowering drugs on plasma homocysteine levels. Expert Opin Drug Saf. 2004;3:101-11.

48. Luc G, Jacob N, Bouly M, Fruchart JC, Staels B, Giral P. Fenofibrate increases homocystinemia through a PPARalpha-mediated mechanism. J Cardiovasc Pharmacol. 2004;43:452-3.

49. Third Report of the National Cholesterol Education Program (NCEP) Expert Panel on Detection, Evaluation, and Treatment of High Blood Cholesterol in Adults (Adult Treatment Panel III) final report. Circulation. 2002;106:3143-421.

50. Grundy SM, Cleeman JI, Merz CN, Brewer Jr HB, Clark LT, Hunninghake DB, et al. Implications of recent clinical trials for the National Cholesterol Education Program Adult Treatment Panel III Guidelines. J Am Coll Cardiol. 2004:44:720-32. 
51. Baigent C, Keech A, Kearney PM, Blackwell L, Buck G, Pollicino C, et al. Efficacy and safety of cholesterol-lowering treatment: prospective meta-analysis of data from 90,056 participants in 14 randomised trials of statins. Lancet. 2005;366:1267-78.

52. Mills EJ, Wu P, Chong G, Ghement I, Singh S, Akl EA, et al. Efficacy and safety of statin treatment for cardiovascular disease: a network meta-analysis of 170255 patients from 76 randomized trials. QJM. 2011;104:109-24.

53. Hermans MP, Castro Cabezas M, Strandberg T, Ferrieres J, Feely J, Elisaf M, et al. Centralized Pan-European survey on the under-treatment of hypercholesterolaemia (CEPHEUS): overall findings from eight countries. Curr Med Res Opin. 2010;26:445-54.

54. Elisaf MS, Nikas N. Centralized Pan-European survey on the undertreatment of hypercholesterolemia in patients using lipid lowering drugs - the CEPHEUS-Greece survey. Angiology. 2010;61:465-74.

55. da Silva PM, Cardoso SM. Persistent lipid abnormalities in patients treated with statins: Portuguese results of the Dyslipidemia International Study (DYSIS). Rev Port Cardiol. 2011;30:4763.

56. Fruchart JC, Sacks F, Hermans MP, Assmann G, Brown WV, Ceska R, et al. The Residual Risk Reduction Initiative: a call to action to reduce residual vascular risk in patients with dyslipidemia. Am J Cardiol. 2008;102:1K-34K.

57. Armitage J, Bowman L, Wallendszus K, Bulbulia R, Rahimi K, Haynes R, et al. Intensive lowering of LDL cholesterol with $80 \mathrm{mg}$ versus $20 \mathrm{mg}$ simvastatin daily in 12,064 survivors of myocardial infarction: a double-blind randomised trial. Lancet. 2010;376:165869.

58. Alsheikh-Ali AA, Lin JL, Abourjaily P, Ahearn D, Kuvin JT, Karas RH. Prevalence of low high-density lipoprotein cholesterol in patients with documented coronary heart disease or risk equivalent and controlled low-density lipoprotein cholesterol. Am J Cardiol. 2007;100:1499-501.

59. Sarwar N, Danesh J, Eiriksdottir G, Sigurdsson G, Wareham N, Bingham S, et al. Triglycerides and the risk of coronary heart disease: 10,158 incident cases among 262,525 participants in 29 Western prospective studies. Circulation. 2007;115:450-8.

60. Tellis CC, Tselepis AD. The role of lipoprotein-associated phospholipase A2 in atherosclerosis may depend on its lipoprotein carrier in plasma. Biochim Biophys Acta. 2009;1791:327-38.

61. Gazi IF, Tsimihodimos V, Tselepis AD, Elisaf M, Mikhailidis DP. Clinical importance and therapeutic modulation of small dense low-density lipoprotein particles. Expert Opin Biol Ther. 2007;7:53-72.

62. Hingorani AD, Shah T, Casas JP, Humphries SE, Talmud PJ. Creactive protein and coronary heart disease: predictive test or therapeutic target? Clin Chem. 2009;55:239-55.

63. Filippatos TD, Tsimihodimos V, Kostapanos M, Kostara C, Bairaktari E, Kiortsis DN, et al. Small dense LDL cholesterol and apolipoproteins $\mathrm{C}$-II and C-III in non-diabetic obese subjects with metabolic syndrome. Arch Med Sci. 2008;4:263-9.

64. Seifalian AM, Filippatos TD, Joshi J, Mikhailidis DP. Obesity and arterial compliance alterations. Curr Vasc Pharmacol. 2010;8:15568.

65. Rizzo M, Rini GB, Berneis K. Effects of statins, fibrates, rosuvastatin, and ezetimibe beyond cholesterol: the modulation of LDL size and subclasses in high-risk patients. Adv Ther. 2007;24:57582 .

66. Saougos VG, Tambaki AP, Kalogirou M, Kostapanos M, Gazi IF, Wolfert RL, et al. Differential effect of hypolipidemic drugs on lipoprotein-associated phospholipase A2. Arterioscler Thromb Vasc Biol. 2007;27:2236-43.

67. Ai M, Otokozawa S, Asztalos BF, Nakajima K, Stein E, Jones PH, et al. Effects of maximal doses of atorvastatin versus rosuvastatin on small dense low-density lipoprotein cholesterol levels. Am J Cardiol. 2008;101:315-8.

68. Nakou ES, Filippatos TD, Agouridis AP, Kostara C, Bairaktari ET, Elisaf MS. The effects of ezetimibe and/or orlistat on triglyceriderich lipoprotein metabolism in obese hypercholesterolemic patients. Lipids. 2010;45:445-50.

69. Tzotzas T, Filippatos TD, Triantos A, Bruckert E, Tselepis AD, Kiortsis DN. Effects of a low-calorie diet associated with weight loss on lipoprotein-associated phospholipase A2 (LpPLA2) activity in healthy obese women. Nutr Metab Cardiovasc Dis. 2008; 18:477-82.

70. Nakou ES, Filippatos TD, Georgoula M, Kiortsis DN, Tselepis AD, Mikhailidis DP, et al. The effect of orlistat and ezetimibe, alone or in combination, on serum LDL and small dense LDL cholesterol levels in overweight and obese patients with hypercholesterolaemia. Curr Med Res Opin. 2008;24:1919-29.

71. Kalogirou M, Tsimihodimos V, Gazi I, Filippatos T, Saougos V, Tselepis AD, et al. Effect of ezetimibe monotherapy on the concentration of lipoprotein subfractions in patients with primary dyslipidaemia. Curr Med Res Opin. 2007;23:1169-76.

72. Kostapanos MS, Milionis HJ, Filippatos TD, Nakou ES, Bairaktari ET, Tselepis AD, et al. A 12-week, prospective, open-label analysis of the effect of rosuvastatin on triglyceride-rich lipoprotein metabolism in patients with primary dyslipidemia. Clin Ther. 2007;29:1403-14.

73. Florentin M, Tselepis AD, Elisaf MS, Rizos CV, Mikhailidis DP, Liberopoulos EN. Effect of non-statin lipid lowering and antiobesity drugs on LDL subfractions in patients with mixed dyslipidaemia. Curr Vasc Pharmacol. 2010;8:820-30.

74. Agouridis AP, Filippatos TD, Tsimihodimos V, Elisaf MS. Combinations of ezetimibe with nonstatin drug regimens affecting lipid metabolism. Expert Rev Cardiovasc Ther. 2011;9:355-66.

75. Filippatos TD, Elisaf MS. Combination drug treatment in patients with non-alcoholic fatty liver disease. World J Hepatol. 2010;2:139-42.

76. Filippatos T, Derdemezis C, Elisaf M. Effects of orlistat, alone or combined with hypolipidemic drugs, on cardiovascular risk factors. Clin Lipidol. 2009;4:331-41.

77. Filippatos TD, Mikhailidis DP. Lipid-lowering drugs acting at the level of the gastrointestinal tract. Curr Pharm Des. 2009;15:490 516

78. Winkler K, Schewe T, Putz G, Odunc N, Schafer G, Siegel E, et al. Fluvastatin/fenofibrate vs. simvastatin/ezetimibe in patients with metabolic syndrome: different effects on LDL-profiles. Eur J Clin Invest. 2009;39:463-70.

79. May HT, Anderson JL, Pearson RR, Jensen JR, Horne BD, Lavasani F, et al. Comparison of effects of simvastatin alone versus fenofibrate alone versus simvastatin plus fenofibrate on lipoprotein subparticle profiles in diabetic patients with mixed dyslipidemia (from the Diabetes and Combined Lipid Therapy Regimen Study). Am J Cardiol. 2008;101:486-9.

80. Tribble DL, Farnier M, Macdonell G, Perevozskaya I, Davies MJ, Gumbiner B, et al. Effects of fenofibrate and ezetimibe, both as monotherapy and in coadministration, on cholesterol mass within lipoprotein subfractions and low-density lipoprotein peak particle size in patients with mixed hyperlipidemia. Metabolism. 2008;57:796801.

81. Rizzo M, Berneis K. The clinical significance of the size of lowdensity-lipoproteins and the modulation of subclasses by fibrates. Curr Med Res Opin. 2007;23:1103-11.

82. Farnier M, Perevozskaya I, Taggart WV, Kush D, Mitchel YB. VAP II analysis of lipoprotein subclasses in mixed hyperlipidemic patients on treatment with ezetimibe/simvastatin and fenofibrate. J Lipid Res. 2008;49:2641-7.

83. Filippatos TD, Gazi IF, Liberopoulos EN, Athyros VG, Elisaf MS, Tselepis $\mathrm{AD}$, et al. The effect of orlistat and fenofibrate, alone or in 
combination, on small dense LDL and lipoprotein-associated phospholipase A2 in obese patients with metabolic syndrome. Atherosclerosis. 2007; 193:428-37.

84. Tsimihodimos V, Liberopoulos E, Elisaf M. Pleiotropic effects of fenofibrate. Curr Pharm Des. 2009;15:517-28.

85. Tsimihodimos V, Kakafika A, Tambaki AP, Bairaktari E, Chapman MJ, Elisaf M, et al. Fenofibrate induces HDL-associated PAF-AH but attenuates enzyme activity associated with apoB-containing lipoproteins. J Lipid Res. 2003;44:927-34.

86. Wu TJ, Ou HY, Chou CW, Hsiao SH, Lin CY, Kao PC. Decrease in inflammatory cardiovascular risk markers in hyperlipidemic diabetic patients treated with fenofibrate. Ann Clin Lab Sci. 2007;37:158-66.

87. Filippatos TD, Liberopoulos EN, Kostapanos M, Gazi IF, Papavasiliou EC, Kiortsis DN, et al. The effects of orlistat and fenofibrate, alone or in combination, on high-density lipoprotein subfractions and pre-beta1-HDL levels in obese patients with metabolic syndrome. Diabetes Obes Metab. 2008; 10:476-83.

88. Hiukka A, Leinonen E, Jauhiainen M, Sundvall J, Ehnholm C, Keech AC, et al. Long-term effects of fenofibrate on VLDL and HDL subspecies in participants with type 2 diabetes mellitus. Diabetologia. 2007;50:2067-75.

89. Ginsberg HN, Elam MB, Lovato LC, Crouse 3rd JR, Leiter LA, Linz P, et al. Effects of combination lipid therapy in type 2 diabetes mellitus. N Engl J Med. 2010;362:1563-74.

90. Ridker PM, Danielson E, Fonseca FA, Genest J, Gotto Jr AM, Kastelein JJ, et al. Reduction in C-reactive protein and LDL cholesterol and cardiovascular event rates after initiation of rosuvastatin: a prospective study of the JUPITER trial. Lancet. 2009;373:117582. 